\title{
Significance of Medication Reconciliation in Intercepting Admission Medication Errors in the General Medicine Department
}

\author{
V. S. MEDA, K. L. P. BABU ${ }^{1}$, V. PRASANNA REDDY ${ }^{2 *}$, M. MOUNIKA², S. SEKHAR REDDY² AND Y. MANASA REDDY² \\ Department of Pharmacy Practice, P. Rami Reddy Memorial College of Pharmacy, ${ }^{1}$ Department of General Medicine, \\ Government General Hospital, Rajiv Gandhi Institute of Medical Sciences, 2Pharm D Intern, P. Rami Reddy Memorial College \\ of Pharmacy, Kadapa, Andhra Pradesh 516003, India
}

\section{Meda et al.: Significance of Medication Reconciliation at Admission}

\begin{abstract}
The aim of the study was to monitor the discrepancies at admission and during the treatment. A prospective observational study was conducted for a period of 6 mo at a South Indian Tertiary Care Hospital. The study was conducted according to the retrospective model of medication reconciliation. Best possible medication history was collected on interacting with patients, caregivers and medical records. This information was compared with the physician's prescription at the time of admission. Differences were documented as intentional and unintentional discrepancies. Identified errors were classified based on National Coordinating Council for Medication Error Reporting and Prevention Guidelines. Drug-drug interactions were classified according to their severity. Errors were rectified before reaching the patient. Out of 106 prescriptions, $44(84.62 \%)$ intentional and $8(15.38 \%)$ unintentional discrepancies were identified. We have also identified $46(43.40 \%)$ medication errors, $60 \%$ of medication errors were of incomplete prescriptions and $26(56.52 \%)$ prescriptions were intervened. We have identified 203 possible drug-drug interactions with an average of $1.92( \pm 2.71)$ per prescription. Among them $105(51.72 \%)$ were major, $90(44.33 \%)$ were moderate and $8(11.66 \%)$ were minor. Our study concludes that lack of medication reconciliation leads to medication errors and on the successful implementation of the medication reconciliation, as a tool in detecting and rectifying admission medication errors, we can increase patient safety.
\end{abstract}

Key words: Medication reconciliation, medication discrepancies, medication errors, omission

One of the main concerns to improve patient safety is medication reconciliation and it was recognized and stated by the Institute for Healthcare Improvement and the Joint Commission. These organizations stated and proved that medication reconciliation reduces the occurrence of adverse events and medication errors. To provide patient safety, health care professionals had to struggle and it is essential to recognize and analyse the reason for medication errors in order to avoid. Medications are one of the primary causes of medication errors in hospital admitted patients with regular usage ${ }^{[1]}$. Medication errors augmented the risk of patient harm due to lack of medication reconciliation and it was identified by the United States Joint Commission for Accreditation of Healthcare Organizations, U.S Joint Commission on Accreditation of Healthcare Organizations (JCAHO) in 2013 and incorporated as an approach to get better patient

*Address for correspondence E-mail: prasannareddy280@gmail.com

September-October 2021 care $^{[2]}$. Within the health care organization the process of identifying the most precise list of all medications which the patient is using including the name, dosage, frequency, route and by furnishing of exact medication to the patient is known as medication reconciliation ${ }^{[3]}$, to avoid medication errors and to get patient safety at all interfaces (admission, transfer and discharge) is the main goal of this process ${ }^{[1]}$.

This reconciliation is done whenever new medications are added or prescribed or the existing medication orders are rewritten at every transition of care, in order to avoid medication errors ${ }^{[3]}$ : The accurate medication history

This is an open access article distributed under the terms of the Creative
Commons Attribution-NonCommercial-ShareAlike 3.0 License, which
allows others to remix, tweak, and build upon the work non-commercially,
as long as the author is credited and the new creations are licensed under
the identical terms

Accepted 08 September 2021 Revised 04 August 2021

Received 04 February 2020 Indian J Pharm Sci 2021;83(5):925-930 
was one of the patient safety solutions disseminated in 2007 by the World Health Organization ${ }^{[4]}$. The main aim of this process is to eliminate undocumented intentional discrepancies and unintentional discrepancies by reconciling all medications, at all stages of patient care $^{[1]}$. Adverse drug events were minimized and get better medications to use safety by medication reconciliation and it was supported by various studies. During hospital admission, $37 \%$ of discrepancies were reported by Abuyassin et al. ${ }^{[4]}$. During discharge, $60 \%$ of medication errors and $20 \%$ of adverse events were observed by Herrero-Herrero and Garcia-Aparicio ${ }^{[5]}$, Karapinar-Carkit et al. ${ }^{[6]}$ and Wong et al. ${ }^{[7]}$ and as per the National study on hospitalization-related adverse events, the incidence rate of adverse events in patients was $9.3 \%^{[8]}$. As per the National study on hospitalization-related adverse events, the incidence rate of adverse events in patients was $9.3 \%$. Up to $60 \%$ of hospitalized patients contain at least one discrepancy in their admission medication history ${ }^{[1]}$. One study showed around $6 \%$ of patients will experience unintentional drug discontinuation of severity (serious nature) on admission to the hospital. Unfortunately, most studies not succeeded to discriminate among unintentional and intentional discrepancies done by the prescriber at the patient's clinical status on admission ${ }^{[8]}$. Triggering factors for a more number of discrepancies are higher age, patient's lack of understanding of his/her drug treatment, inadequate or incomplete drug history, exist more than one medical/ medication record for each patient, long periods in hospital, comorbidity, polypharmacy and transitions inpatient care at weekends ${ }^{[8]}$. Triggering factors for a more number of discrepancies are higher age, patient's lack of understanding of his/her drug treatment, inadequate or incomplete drug history, exist more than one medical/medication record for each patient, long periods in hospital, comorbidity, polypharmacy and transitions inpatient care at weekends ${ }^{[9]}$. The safety of patients depends on the process of communication of error on the adequate report record information and monitoring itself, it all depends on part of health care professionals ${ }^{[10]}$. The objective of this study is to prospectively identify unintended discrepancies between the physician's admission medication orders and a comprehensive medication use history obtained by a pharmacist.

\section{MATERIALS AND METHODS}

After obtaining approval from the Institutional Ethical Committee [Rc.No.3308/Acad./2018] 106 patients of both genders with $>18$ y of age, who were admitted to the general medicine department in Government General Hospital-Rajiv Gandhi Institute of Medical Sciences, Kadapa with a past medical history were interviewed and data was collected by using specific data collection forms after obtaining an informed consent form.

The collected data includes the patient's demographics (age, gender and social habits), past medical and medication history and present prescription details. After the collection of data, discrepancies were identified by using the medication reconciliation process. Steps involved in medication reconciliation are: obtain a Best Possible Medication History (BPMH); confirm the accuracy of the history; reconcile BPMH with prescribed medications; supplying accurate medicines information $^{[11]}$.

Identified discrepancies were discussed with the respective prescriber to know the reason for the discrepancy. If it was unintentional we tried to rectify those discrepancies. All the unintentional discrepancies were enquired or cross-checked with the respective prescriber to know the reason and to rectify the discrepancies (if required). The observed Drug-Related Problems (DRPs) were documented by using the standard form. We have also monitored study subjects throughout their hospital stay to find and intervene in any unintentional discrepancies and DRPs in the prescription.

Statistical analysis includes Microsoft Excel and descriptive statistics include standard deviation, average and percentage were used for analysis of results.

\section{RESULTS AND DISCUSSION}

Out of 106 study subjects, males were $44(41.5 \%)$ and females were $62(58.49 \%)$. We noted that the majority of the subjects were menopause women. The average age of the total study subjects $(n=106)$ is $57.82( \pm 13.79)$ $\mathrm{y}$, the average age of the male subjects is $57.93( \pm 13.81)$ $\mathrm{y}$, whereas females subjects age is $57.41( \pm 13.88) \mathrm{y}$. Out of 106 subjects, 35 (33.02\%) were from 60-69 y age group followed by 70-79 age group i.e., 25 (23.58 $\%), 50-59$ age group i.e., 17 (16.04\%). With this study, we observed that the majority of the subjects were from above 60 y i.e., 63 (59\%), which indicates that the geriatrics are admitting in the general medicine with one or more chronic diseases than adults (43, $41 \%$ ), as geriatrics are at higher risk of developing diseases. Studies conducted by Knez et al. ${ }^{[12]}$ have also reported 
that the subjects $>60$ y are being suffered by diseases. Subject's demographics were depicted in Table 1.

Knowledge about their disease and medications which helps to prevent the errors relating to medications is important and of 106 subjects, $68(64.15 \%)$ subjects were found to be illiterates. 58 (54.72\%) subjects have knowledge about their medication use and illness and the remaining 48 (45.28\%) subjects were lacking this. Our study results were supported by the studies conducted by Safeer et al. ${ }^{[13]}$, Smith et al. ${ }^{[14]}$ who stated that health literacy and good knowledge about the illness and medication usage is important to maintain the communication with the health care professionals, to follow the self-care steps and treatment regimen strictly with greater efficiency and these subjects are less prone to medication errors and helps in decreasing the unnecessary cost expenditure.

Out of 106 subjects included in the study, 29 (27.36\%) subjects were diagnosed with Central Nervous System (CNS) disorders followed by respiratory disorders, Cardiovascular System (CVS) and gastrointestinal disorders. For successful medication reconciliation, getting complete past and present medical history is one of the imperative processes and is the initial step in this process and we had collected the co-morbidities of our study subjects and found that on average each subject is suffering from $1.47( \pm 0.70)$ diseases. And the average duration of the disease suffering is $5.14( \pm 4.30)$ y. We have distributed the co-morbidities according to the system affected and depicted in Table 2.

For the successful implementation of medication reconciliation, the information regarding past medication usage is the chief element. As it helps in the reduction of medication errors and prevents the prescribing of contraindicated and allergic drugs to the patient. We observed/noted 349 drugs are being used by the 106 subjects before their hospital admission, at an average of $3.29( \pm 2.31)$ drugs per subject.
Among 106 prescriptions 52 discrepancies were identified, of which $44(84.62 \%)$ were intentional discrepancies, $8 \quad(15.38 \%)$ were unintentional discrepancies, which were neither documented nor instructed. Among 44 intentional discrepancies observed, 21 (47.73\%) were documented in the patient's medical record and undocumented were found to be $23(52.27 \%)$. The results were depicted in Table 3 and Table 4.

Rational drug therapy can be achieved through proper history taking and documentation in patient's medical record, in our study we observed that the majority of the prescriptions didn't have the proper history of the patient; we interacted with the patients and collected the past and present medical history. The majority of the prescribers are busy and they don't have much time to inquire and document the patient's medical and medication history in this study setup, which may be the reason for most of the unintentional discrepancies. Our study results were supported by Khansa et al. ${ }^{[3]}$ who stated that discrepancies were alarmingly high and these discrepancies may cause potential harm to the patients. A study conducted by Lau et al. ${ }^{[15]}$ shows that $61 \%$ of all patients of their study had one or more discrepancies, while $17 \%$ had three or more discrepancies.

Among the prescriptions with intentional discrepancies, the drugs involved in the discrepancies were depicted in Table 5, among 46 medication errors, we found incomplete prescription is the major $(60.86 \%)$ type of error, which includes not mentioning of doses to the drugs like B complex, calcium and Vitamin D3, followed by untreated indication $43.47 \%$, which includes low hemoglobin levels, cough and duplication $4.34 \%$, which may be due to busy schedule of physicians. Errors observed in our study were depicted in Table 6.

Our study results were supported by Khansa et al. ${ }^{[3]}$ who stated that untreated indication is the major error that occurs during the treatment

\section{TABLE 1: DEMOGRAPHICS OF SUBJECTS}

\begin{tabular}{lccccccc}
\hline S. No & Age $(\mathrm{y})$ & Male $(\mathrm{n}=\mathbf{4 4})$ & $\%$ & Female $(\mathrm{n}=\mathbf{6 2})$ & $\%$ & Total $\mathrm{n}=106$ & $\%$ \\
\hline 1 & $20-29$ & 1 & 2.27 & 2 & 3.22 & 3 & 2.83 \\
2 & $30-39$ & 5 & 11.36 & 4 & 7.02 & 9 & 8.49 \\
3 & $40-49$ & 4 & 9.09 & 10 & 16.12 & 14 & 13.21 \\
4 & $50-59$ & 8 & 18.18 & 9 & 14.51 & 17 & 16.04 \\
5 & $60-69$ & 14 & 31.82 & 21 & 33.87 & 35 & 33.02 \\
6 & $70-79$ & 11 & 25.00 & 14 & 22.58 & 25 & 23.58 \\
7 & $80-89$ & 1 & 2.27 & 2 & 3.22 & 3 & 2.83 \\
\hline
\end{tabular}


course which may be due to the busy schedule of the physicians.

The knowledge of the severity of the error is necessary to prevent harm to the subject. We classified the severity of the errors based on the National Coordinating Council for Medication Error Reporting and Prevention (NCC MERP) classification ${ }^{[16]}$. In this study, we observed that the majority of errors belong to Category E (53\%) which may result in temporary harm

\section{TABLE 2: SYSTEM INVOLVED IN CO-MORBIDITY}

\begin{tabular}{lccc}
\hline S. No & $\begin{array}{c}\text { System involved in co- } \\
\text { morbidities }\end{array}$ & $\begin{array}{c}\text { No. of } \\
\text { subjects }\end{array}$ & $\%$ \\
\hline 1 & CVS & 74 & 74.75 \\
2 & Endocrine System & 42 & 42.42 \\
3 & CNS & 12 & 12.12 \\
4 & Respiratory System & 6 & 6.06 \\
5 & Miscellaneous & 3 & 3.03 \\
\hline
\end{tabular}

TABLE 3: DISCREPANCIES OBSERVED

\begin{tabular}{lccc}
\hline S. No & Discrepancy & $\begin{array}{c}\text { No. of prescriptions } \\
\mathrm{n}=52\end{array}$ & $\%$ \\
\hline 1 & Intentional & 44 & 84.62 \\
2 & Un Intentional & 8 & 15.38 \\
\hline
\end{tabular}

TABLE 4: DOCUMENTATION OF DISCREPANCIES

\begin{tabular}{lccc}
\hline S. No & $\begin{array}{c}\text { Intentional } \\
\text { discrepancy }\end{array}$ & $\begin{array}{c}\text { No. of } \\
\text { prescriptions } \\
\mathrm{n}=\mathbf{4 4}\end{array}$ & $\%$ \\
\hline 1 & Documented & 21 & 47.73 \\
2 & Not Documented & 23 & 52.27 \\
\hline
\end{tabular}

TABLE 5: CATEGORY OF THE DRUGS INVOLVED IN INTENTIONAL DISCREPANCIES

\begin{tabular}{lcc}
\hline S. No & Category of drugs involved & $\begin{array}{c}\text { No. of drugs } \\
\text { involved }\end{array}$ \\
\hline 1 & Cardiovascular Drugs & 39 \\
2 & Anti-Hyperglycaemic Drugs & 21 \\
3 & Antacids & 4 \\
4 & Respiratory System Drugs & 5 \\
5 & Antibiotics & 4 \\
6 & Miscellaneous & 25 \\
\hline
\end{tabular}

TABLE 6: TYPE OF ERRORS OBSERVED

\begin{tabular}{lcccc}
\hline S. No & Type of error & No. of prescriptions $(\mathbf{n}=46)$ & $\%$ & No. of drugs involved \\
\hline 1 & Drug Without Indication & 1 & 2.17 & 1 \\
2 & Duplication & 2 & 4.34 & 2 \\
3 & Incomplete Prescription & 28 & 60.86 & 44 \\
4 & Adverse Drug Reaction & 2 & 4.347 & 2 \\
5 & Wrong Frequency & 1 & 2.17 & 1 \\
6 & Missed Drug & 1 & 2.17 & 1 \\
7 & Over Dose & 1 & 2.17 & 1 \\
8 & Untreated Indication & 20 & 43.47 & 20 \\
\hline
\end{tabular}

and which needs intervention. Our study results were supported by Hayward et al. ${ }^{[17]}$ who stated that most of the medication errors may result in increasing the severity of the patient's condition. It is clearly designed in Table 7.

The knowledge of the possible Drug-Drug Interactions (DDIs) is necessary to prevent possible harm to the patients and to follow the required monitoring parameters. With this study, we found more than $50 \%$ of prescriptions contain the interacting combination of drugs. It is not possible to change the prescriptions with possible DDIs as these drugs are needed by them, so they must be categorized and based on the category and risk factors, healthcare professionals need to take precautions to avoid their adverse consequences. In our study we assessed the severity and found the majority of the DDIs were major ( $51.72 \%$ ), followed by moderate (45.32), this indicates the majority of the patients are receiving prescriptions contains major DDIs without any precautions, but fortunately, no patient reported any adverse consequence.

The most commonly prescribed DDI combination in our study subjects was Aspirin+Clopidogrel and prescribed in 24 subjects followed by Atorvastatin+Clopidogrel in 20 subjects, these either in combination or alone or in combination with other drugs are proven to be most effective for CVD, so it is not advisable to change. The detailed description was depicted in Table 8 . Our study results were supported by Babu et al. ${ }^{[18]}$ who stated that moderate possible DDIs were common in the prescription containing cardiovascular drugs.

Pharmacist's intervention is a vital activity to be done to identify and prevent medication errors, which may cause harm to the patient and improves patient care. Among 44 prescriptions with errors, 26 prescriptions were intertwined. More than half of the unintentional discrepancies were rectified by us after discussing it with the concerned prescriber. Out of 27 interventions, in around $90 \%$ of prescriptions, the missed drug was added. The results were depicted in Table 9. Our study results were supported by Salameh et al. ${ }^{[19]}$ who stated 
TABLE 7: SEVERITY OF THE ERRORS OBSERVED

\begin{tabular}{lccc}
\hline S. No & Severity of error & No. of prescriptions $(\mathrm{n}=46)$ & $\%$ \\
\hline 1 & Category A & 21 & 45.65 \\
2 & Category B & 1 & 2.17 \\
3 & Category C & 1 & 2.17 \\
4 & Category E & 23 & 50 \\
\hline
\end{tabular}

TABLE 8: SIGNIFICANT POSSIBLE DDIS OBSERVED

\begin{tabular}{|c|c|c|c|c|}
\hline S. No & Category & Interacting drugs & Possible consequences as per literature & No. of prescriptions \\
\hline 1 & Major & Aspirin+Clopidogrel & Increases the risk of bleeding & 24 \\
\hline 2 & Major & Aspirin+Furosemide & $\begin{array}{c}\text { Reduced diuretic effectiveness, possible } \\
\text { nephrotoxicity }\end{array}$ & 9 \\
\hline 3 & Major & Atorvastatin+Digoxin & Increased plasma concentration of digoxin & 7 \\
\hline 4 & Major & Aspirin+Metformin & Increased risk of hypoglycaemia & 7 \\
\hline 5 & Major & Aspirin+Spironolactone & $\begin{array}{l}\text { Reduced diuretic effectiveness, hyperkalaemia, } \\
\text { possible nephrotoxicity }\end{array}$ & 6 \\
\hline 6 & Moderate & Atorvastatin+Clopidogrel & $\begin{array}{c}\text { Decreased formation of clopidogrel active } \\
\text { Metabolite resulting in high on treatment platelet } \\
\text { activity }\end{array}$ & 20 \\
\hline 7 & Moderate & Aspirin+Metoprolol & Increases the risk of hypertension & 7 \\
\hline 8 & Moderate & Aspirin+Enalapril & Decreased effectiveness of enalapril & 6 \\
\hline 9 & Moderate & Aspirin+Carvedilol & Increases the risk of hypertension & 5 \\
\hline 10 & Moderate & Pantop+Iron & Reduces the iron bioavailability & 4 \\
\hline 11 & Minor & Aspirin+Rantac & Decreased activity of aspirin & 3 \\
\hline
\end{tabular}

TABLE 9: PHARMACIST'S INTERVENTION PERFORMED

\begin{tabular}{lccc}
\hline S. No & Intervention & Number of prescriptions & $\%$ \\
\hline 1 & Added Drug & 20 & 74.07 \\
2 & Added Dose & 2 & 7.40 \\
3 & Prescription Correction & 2 & 7.40 \\
4 & Drug Removal & 1 & 3.70 \\
5 & Changed Frequency & 1 & 3.70 \\
6 & Reduced Dose & 1 & 3.70 \\
\hline
\end{tabular}

that unintended medication variances are common. Intervention is necessary to eliminate those errors and to prevent harm. Medication reconciliation was a successful tool for detecting and rectifying medication errors.

In the current research, omission was the major intentional discrepancy observed. Fortunately, no patient had experienced any consequences of DDIs. Incomplete prescription and the untreated indication were the major types of errors observed. About $50 \%$ of the medication errors were corrected and prevented from causing harm to the patient by using Pharmacist's based medication reconciliation. The results show that, on implementation of medication reconciliation before writing the prescription to the admitted patients helps in reducing the majority of the discrepancies. With these findings, we suggest the implementation of standard medication reconciliation process at the study hospital and also patients need to be educated about the importance of their medical records to improve the patient care. The limitation of this research is low sample size and similar studies with higher sample size are needed to strengthen our findings.

\section{Acknowledgment:}

Authors wish to thank study subjects, health care professionals, who provided the utmost support for the successful completion of our research study.

\section{Conflict of interests:}

The authors report no conflicts of interest regarding this work. The authors alone are responsible for the content and writing of the paper.

\section{REFERENCES}

1. Al-Rashoud I, Al-Ammari M, Al-Jadhey H, Alkatheri A, Poff $\mathrm{G}$, Aldebasi T, et al. Medication discrepancies identified during Medication reconciliation among medical patients at a tertiary care hospital. Saudi Pharm J 2017;25(7):1082-85.

2. Magalhaes GF, Santos GB, Rosa MB, Noblat LD. Medication reconciliation in patients hospitalized in a cardiology unit. 
PloS one 2014;9(12):e115491.

3. Khansa SA, Mukhtar A, Abduljawad M, Aseeri M. Impact of Medication Reconciliation upon Discharge on Reducing Medication Errors. J Pharmacovigil 2016;4(06):1-5.

4. AbuYassin BH, Aljadhey H, Al-Sultan M, Al-Rashed S, Adam M, Bates DW. Accuracy of the medication history at admission to hospital in Saudi Arabia. Saudi Pharm J 2011;19(4):263-7.

5. Herrero-Herrero J, García-Aparicio J. Medication discrepancies at discharge from an internal medicine service. Eur $\mathrm{J}$ Intern Med 2011;22(1):43-8.

6. Karapinar-Carkit F, Borgsteede SD, Zoer J, Smit HJ, Egberts AC, Bemt PM. Medication safety: effect of medication reconciliation with and without patient counselling on the number of pharmaceutical interventions among patients discharged from the hospital. Ann Pharmacother 2009;43(6):1001-10.

7. Wong JD, Bajcar JM, Wong GG, Alibhaj SM, Huh JH, Cesta A, et al. Medication reconciliation at hospital discharge: Evaluating Discrepancies. Ann Pharmacotherapy 2008;42(10):1373-9.

8. Cornish PL, Knowles SR, Marchesano R, Tam V, Shadowitz S, Juurlink DN, et al. Unintended medication discrepancies at the time of hospital admission. Arch Intern Med 2005;165(4):4249.

9. Durán-García E, Fernandez-Llamazares CM, CallejaHernández MA. Medication reconciliation: passing phase or real need?. Int J Clin Pharm 2012;34(6):797-802.

10. Dalmolin GR, Rotta ET, Goldim JR. Medication errors: classification of seriousness, type, and of medications involved in the reports from a University Teaching Hospital. Braz J
Pharm Sci 2013;49(4):793-802.

11. Assuring Medication Accuracy at Transitions in Care: Medication Reconciliation. The High 5s Project Standard Operating Protocol; 2014. p. 1-2

12. Knez L, Suskovic S, Rezonja R, Laaksonen R, Mrhar A. The need for medication reconciliation: A cross-sectional observational study in adult patients. Respir Med 2011;105 :60-6.

13. Safeer RS, Cooke CE, Keenan J. The impact of health literacy on cardiovascular disease. Vasc Health Risk Manag 2006;2(4):457-64.

14. Smith B, Sullivan E, Bauman A, Powell-Davies G, Mitchell J. Lay beliefs about the preventability of major health conditions. Health Educ Res 1999;14(3):315-25.

15. Lau HS, Florax C, Porsius AJ, De Boer A. The completeness of medication histories in hospital medical records of patients admitted to general internal medicine wards. $\mathrm{Br} \mathrm{J}$ Clin Pharmacol 2000;49(6):597-603.

16. Classification of medication errors. The National Coordinating Council for Medication Error Reporting and Prevention; 2018.

17. Hayward RA, Hofer TP. Estimating hospital deaths due to medical errors: preventability is in the eye of the reviewer. Jama 2001;286(4):415-20.

18. Babu E, Palanichamy H, Vinod N, Ravichandra S, Parthasarathy R. Evaluation of effects of medical reconciliation in renal failure patients in a tertiary care hospital. Int J Pharm Pract 2017; 10(3):166-73.

19. Salameh L, Farha RA, Basheti I. Identification of Mediation discrepancies during hospital admission in Jordan: Prevalence and risk factors. Saudi Pharm J 2018;26(1):125-32. 